\title{
Food Waste reuse as a feed for organic chicken: A case study
}

\author{
Latifa Mechkirrou ${ }^{1,2, *}$, Mourad Arabi ${ }^{3}$, Mohammed Ouhssine ${ }^{1}$, and Mohamed El Amine Afilal ${ }^{2}$ \\ ${ }^{1}$ Laboratory of Agro-Physiology, Biotechnologies, Environment and Qualities, Faculty of Sciences, PB 242 14000, Kenitra, Morocco \\ ${ }^{2}$ Laboratory of bioresources, biotechnologies, Ethnopharmacology and Health, Faculty of Sciences, PB 717 60000, Oujda, Morocco \\ ${ }^{3}$ Laboratory of the Improvement of Agricultural Production, Biotechnology \& the Environment, FS, PB 717 60000, Oujda, Morocco
}

\begin{abstract}
Since the food system will inevitably produce food waste, it is recommended that it be captured and recycled for more efficient use rather than being disposed of as solid household waste. Therefore, it is advantageous to promote food waste as poultry feed. In order to study the feeding feasibility of a poultry LabPrepared Feed (LPF) based on kitchen food waste as well as their nutritional value, the tests were carried out near Taza city on an organic chicken farm, in Eastern Morocco. The results of consumption indices concerning organic chickens treated only by Lab-Prepared Feed showed average values of 1.18 and 1.17 for tests 1 and 2 successively. According to the results obtained, the tests proved the feeding feasibility of a Lab-Prepared Feed (LPF), it appears to be a good substitute for commercial foods. The study may help to ensure the recovering of food waste materials as a new poultry feed substitute.
\end{abstract}

\section{Introduction}

Due to rapid population growth associated with urbanization, which is expected to reach 9.7 billion people by 2050 [1], rates of Municipal Solid Waste (MSW) generation are experiencing a significant increase more than double over the next twenty years in lower income countries [2]. It is predicted that will reach 2.2 billion tons by the end of 2025, moreover, the generation of MSW has a higher rate than urbanization [3], therefore, the same for food waste (FW) which occupies the highest proportion of fermentable household waste [4]. Quantitatively, Moroccan country generates annually more than 9 million tons of MSW, with a daily report of $0.76 \mathrm{Kg}$ per capita in the urban area, of which only $9 \%$ recycled, and $37 \%$ landfilled $[5,6]$. In the city of Oujda, the annual amount of solid waste generated is 152000 tons. In which the proportion of putrescible fraction mainly dominated by Food Waste is on average $74 \%$ and reaches $77 \%$ during the summer season. Unfortunately, this waste is landfilled instead of being recycled, aggravating the negative impact of its treatment within the landfill cells due to its high humidity of $64 \%$ [7].

Indeed, the Food and Agriculture Organization of the United Nations (FAO) has estimated that globally, 1.3 billion tonnes of food waste is landfilled each year $[8,9$, 10], which accounts for up to a third of the total food produced for human consumption. Therefore, disposal of enormous quantities of food waste (FW) is an emerging problem which has a significant influence on global, economic and environmental conditions [10, 11]. However, each available disposal options have serious environmental impacts. On the other hand, food waste contributes to greenhouse gas (GHG) emissions produced at landfills [12], which are estimated at around 3,3 billion tonnes per year of $\mathrm{CO} 2$ into the atmosphere [8, 13], pollution of the aquifer and soil by leachate and the production of odor along with public health issues [12, 14]. In addition, incineration cause a loss of energy due to the evaporation of water, as the humidity reaches up to $82-86 \%$ [4] and is often accompanied by a release of dioxins. As a result, loss of valuable compounds and nutrients contained in this food waste [15].

In this regard, methods are provided as alternatives to conventional methods of treating WF and to facilitate the selection of removal technologies which are preferable. Certainly, according to the hierarchy of food waste management, governments must prioritize efforts to: reduce food waste, redistribute it, recycle it as animal feed and compost, recover energy by anaerobic digestion and finally put the rest in landfill [16].

Certainly, Proper and efficient handling of FW not only serves as a valuable resource but also reduces the impacts on the environment. Since the organic fractions have often a very high nutritional value, one of such suggested use would be the re-feeding of animals with this food waste. They may be used as a fed to livestock, thus, a substitute for traditional feedstuffs for pigs and poultry [17]. However, the FAO declared that 1.25 billion tonnes are used for animal feed. As well, the equivalent dry tonnage of these residues is more likely to provide 1.6 to 1.7 billion tonnes of dry feed for animal [1]. This can contribute significantly to meeting the needs in terms of meat over the country $[16,18]$.

As an original scientific study, in order to reuse of the food waste as a feed for organic chicken, two tests are conducted on 2016 at the eastern region of Morocco. The objective of this study is to check the feeding feasibility and the nutritional value of a poultry Lab-Prepared Feed (LPF) based on kitchen food waste. In addition, to

\footnotetext{
Corresponding author: latifa.mechkirrou@uit.ac.ma
} 
improve the production in poultry, using medicinal plants provided the greatest benefit. Indeed, the several studies by using medicinal plants as an ingredient were carried out. For example, the Thymus vulgaris used by Khan and al. [19] as a growth promoter, and which has shown a qualitative improvement in the meat produced. As well, Zhai and al., proved in numerous in vitro studies that essential oils exert antimicrobial effects on various pathogens [20]. Thus, he touched on the basics of essential oils, and its in-vivo effects on growth, intestinal microflora, antioxidant ability, immune functionality and meat qualities in poultry.

\section{Material and methods}

\subsection{Lab-prepared poultry feed based on kitchen food waste (LPF)}

The lab-prepared food (LPF) for use in poultry farming is made from kitchen wastes (leftovers from meals, fruit and vegetable peels). These wastes are collected from many restaurants in the city of Oujda (Eastern Morocco). The organic part is obtained through a manual sorting operation. Thereafter, it is stabilized, sterilized and then granulated (Fig. 1).

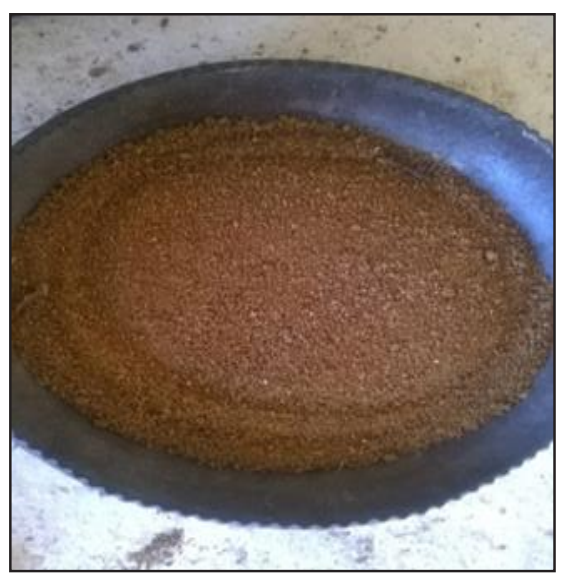

Fig. 1. The lab-prepared food (LPF)

The isolated organic part is initially sun-dried until a mass-stable raw material is obtained. Then this raw material is milled to produce powdery food. Subsequently, a food supplement (based on medicinal plants) is added to this powder to enrich its nutritional value.

This food (LPF) has undergone a characterization allowing the evaluation of its contents in Dry Matter (DM), which is determined through drying at $105^{\circ} \mathrm{C}$ for 24 hours in a ventilated oven [21]. Thereafter, its contents of mineral matter $(\mathrm{MM})$ and organic matter $(\mathrm{OM})$ are determined by calcination at $550^{\circ} \mathrm{C}$ for 2 hours in a thermal incinerator (Muffle furnace) [22, 23, 24].

In order to obtain a granulated feed that can be consumed by the smallest chicks, a manual granulation (with the addition of water) is carried out as a first step. Then, these granules (pellets) are sun-dried until they reach a stable mass (Fig. 2).

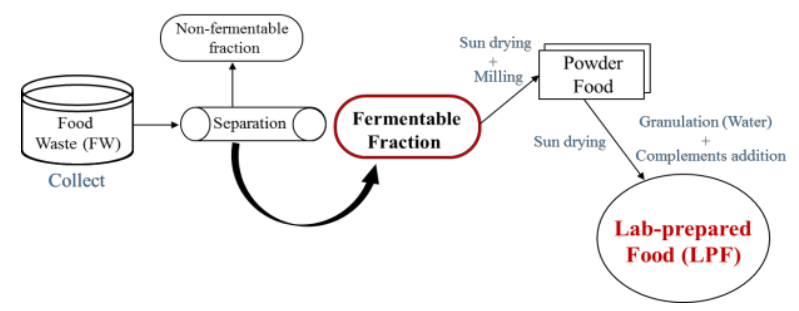

Fig. 2. Schematic of the lab-manufacturing steps of the labprepared food (LPF)

\subsection{Organic chicks breeding test}

For the experimentation study, only one type of foods was considered for the test: the lab-prepared food (LPF) was used as poultry feed (Fig. 1). Two feeding feasibility tests were carried out on a small organic chicken farm, located in the Taza city, Eastern Morocco.

\subsection{Tested organic chickens farming conditions}

As for the two breeding tests occurred for two months in order to check the feeding feasibility using youngest organic broilers. The first test took place from June to August 2016 and the second from July to September 2016. The applied breeding density for each group was 10 subjects $/ \mathrm{m}^{2}$, allowing the respect of the standards of 15 to 20 subjects $/ \mathrm{m}^{2}$ during the whole growth phase (15 to 30 days) [25]. A sample of 20 one-week aged chicks, regardless of sex considering the reason for which these chickens are destined, which is the meat production, was used for each trial. As for the feeding frequency, it was of 3 times/day (at 8:00, 12:00 and 16:00) in cylindrical feeders that can feed up to 50 chickens [26]. In addition, plastic drinkers with a capacity of 5 liters were used to supply them with tap water continuously [27]. Indeed, a liquid-based on a medicinal plant extract was added to these drinkers during the whole period of the experimentation.

Generally, for the two tests occurred in the present study, the weight of each of the subjects was measured at the start of the operation to mark the average weight of all the chicks [28]. For each of the two tests, the monitoring of mortality cases, Feed intake, feed refusals and individual body weights were weighed weekly using an electronic balance (Model SF-400, $\pm 10 \mathrm{~g}$ ). The measurement of food consumption of these chickens was based on the difference between the distributed and the recovered quantities of food, thus, throughout the entire test period and for all occurred experiments [26, 29, 30]. As well, the feed intake could only be calculated groupwise [30]. The weight changes, as well as the rates of food consumed per each week, allowed the calculation of the daily weight gain (DWG), the daily individual food consumption (DIC), the consumption index (CI), carcass yield (CY) and mortality rate (MR), which were evaluated following the formulas [26, 29]:

\section{$D W G(g /$ day $)=[$ Weight gain $(g)] /[$ Duration of the period (days)]}

DIC $(g)=[\{$ Quantity of food served (g/day)-Quantity of food recovered (g/day)\}] / [Number of subjects] 
$C I=[$ Quantity of food consumed in a single week $(g)]$ / [weight gained during the same week $(g)$ ]

$C Y(\%)=100 *[$ subject carcass weight] /[alive subject weight]

MR $(\%)=100 *[($ Initial number of subjects - Final number of subjects)] / [Initial number of subjects]

\subsection{Food supplements composition}

Food supplements have been prepared based on two forms of medicinal plants, powder (using thyme leaves, bay leaf, myrtle, fennel seeds), and liquid (based on citrus fruits, Clinoptilolite essential oils, and emulsifiers). Besides stimulating capacity of the digestive system of the tested subjects, the supplement in powder form improves (following data obtained from the poultry food industrials), their weight gain, their food conversion rate and the quality of their carcass on the one hand. It prevents their physical stress and increases the absorption of nutrients in their small intestine, on the second hand. Thus, for the transformation process, it prevents the decline of feed conversion ratios. Whereas for the supplement in liquid form, it is characterized (in addition to the benefits obtained from the food in powder form) by an ability to reduce the abdominal fatness and the negative effects caused by temperature and physical stress for the subjects. In addition, it increases the quality of drinking water by eliminating pathogens as much as possible.

\section{Results and Discussion}

\subsection{Organic and minimal parameters}

The results of the organic and minimal parameters determined are reported in (Fig. 3). They are obtained from the dry matter (DM) of the samples.

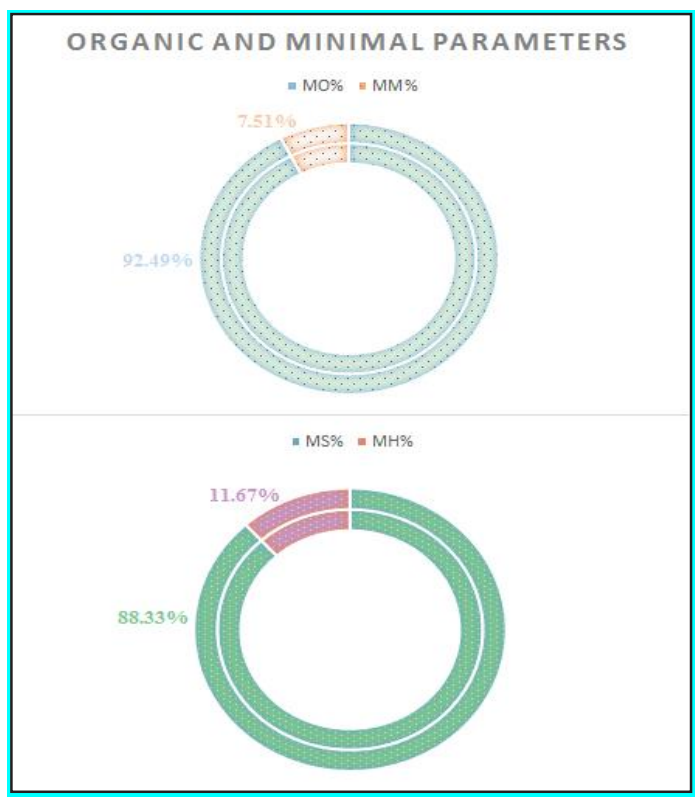

Fig. 3. Organic and minimal parameters of Lab-prepared food (LPF)
The average OM composition is in the neighborhood of $92 \%$ DM which complies with the recommendations (92\%) [31], indicating that food waste contains high levels of OM [32]. While the average rate of mineral matter (MM) is about $7.51 \% \mathrm{DM}$ and that is the same value $(6.1 \%)$ reported by Seven and $a l$. [33].

The average dry matter (DM) content is approximately $88 \%$ MB. This relatively high rate is partly due to pretreatment by drying, sorting and reduction in the size of the kitchen scraps before drying [21], the same observation was made by Lacour [34]. This value is almost the same as that for the diet of broilers (92\%) [35] and $90.8 \%$ [31]. While the average moisture content is around $11 \% \mathrm{DM}$ which is similar to the minimum result $(20 \mathrm{~g} / \mathrm{kg})$ [36].

\subsection{Growth performance}

The measurements made on organic chicks are mentioned in (Fig. 4A and 4B).

According to the results of both test 1 and test 2 (Fig. 4), it can be seen that the rates of the average consumption of the food during the rearing periods are low. Although it shows an evolution during the first 9 weeks of rearing; from $117 \mathrm{~g}$ to $279 \mathrm{~g}$ for the first test, and from $98.7 \mathrm{~g}$ to $238.5 \mathrm{~g}$ for the second test, then it decreases relatively at the end of both tests.

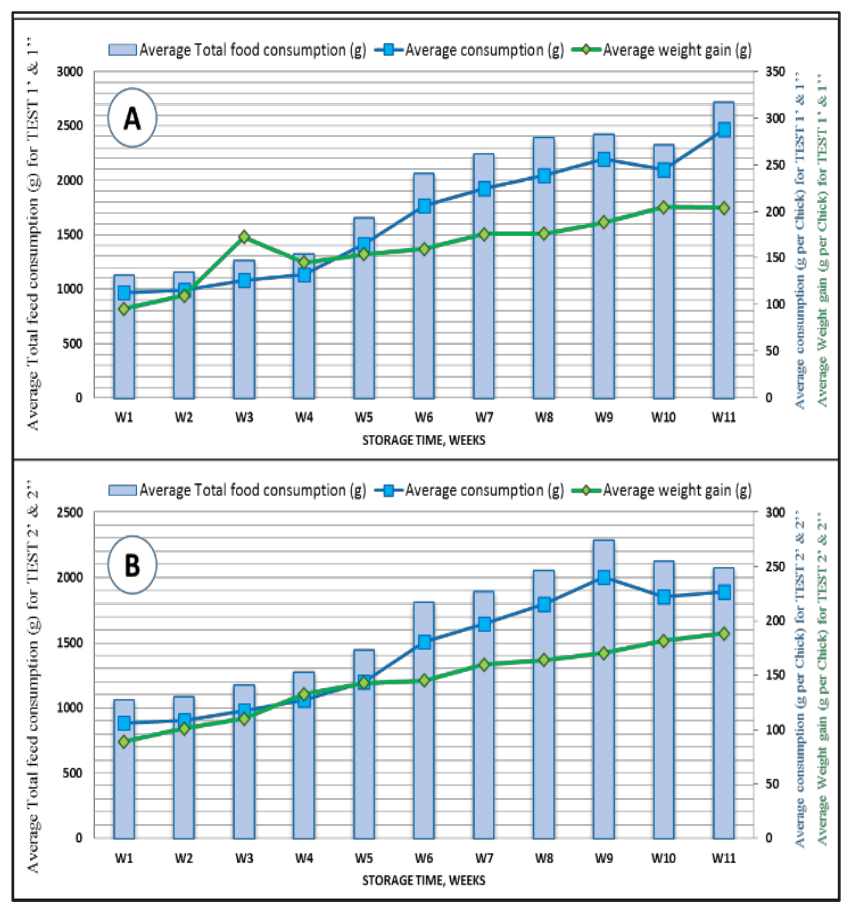

Fig. 4. Average total feed consumption, Average feed consumption, and the weight gain (g) per chick (A: Test 1' \& 1', B: Test 2' \& 2',)

For daily food consumption, the results obtained are lower than the benchmarks recommended by Dusart [37]. Likewise, for daily consumption per chick [38]. However, the average results of food consumption, weight gain, and total food consumption are higher than those reported by Leiber F. and $a l$. at the age over 82 days [30]. 


\subsection{Characteristics of the Carcass and Liver}

For the evaluation of animal performance, all chicks of each experimental unit were assessed to give a group average measurement, thus, made the number of replicate $\mathrm{n}=20(100 \%)$. Furthermore, the carcass, being associated with the determination of the efficiency in terms of feed cost [39], is determined at $89 \mathrm{~d}$ of age when all chicks per experimental unit (10 birds/treatment) were slaughtered following the method of bleeding. For the calculation of the carcass yield, the hot eviscerated carcass weight (eliminating feet, head, and abdominal fat), was considered in relation to the individual bodyweight that was obtained before slaughter [40].

The characteristics of both carcass and liver of chicks have been studied by several researchers, Carew and al. conducted a study on the effects of lysine deficiency on the liver and body weight and food intake in growing chickens. They concluded that liver weight is relative to body weight [41].

The characteristics of the carcass and liver in organic chickens fed with the lab-prepared food (LPF) are mentioned in (Table 1). Indeed, the carcass average's weight, included and without viscera, as well as the liver average's weight obtained in organic chicks are lower.

Table 1. Average Carcass and liver weight measured for organic slaughtered chickens.

\begin{tabular}{|c|c|c|c|c|c|c|}
\hline & \multicolumn{3}{|c|}{$\frac{\text { Test 1 }}{(\mathrm{n}=20)}$} & \multicolumn{3}{|c|}{$\frac{\text { Test 2 }}{(\mathrm{n}=20)}$} \\
\hline & $\frac{\text { Unit 1 }}{(\mathrm{n}=10)}$ & $\frac{\text { Unit 2 }}{(\mathrm{n}=10)}$ & Average & $\frac{\text { Unit 1 }}{(\mathrm{n}=10)}$ & $\frac{\text { Unit 2 }}{(\mathrm{n}=10)}$ & Average \\
\hline $\begin{array}{l}\text { Carcass } \\
\text { weight } \\
\text { included } \\
\text { viscera } \\
\text { (g) }\end{array}$ & 115 & 112.9 & 113.95 & 87.75 & 92.8 & 90.27 \\
\hline $\begin{array}{l}\text { Carcass } \\
\text { weight } \\
\text { without } \\
\text { viscera } \\
\text { (g) }\end{array}$ & 91 & 87.6 & 89.3 & 66.1 & 69.9 & 68 \\
\hline $\begin{array}{l}\text { Liver } \\
\text { weight } \\
\text { (g) }\end{array}$ & 6.43 & 8.2 & 7.31 & 4.69 & 7.96 & 6.32 \\
\hline
\end{tabular}

The results obtained are different from those reported by Leiber and al. [30]. Thus, they found that the weights of both carcass and different meat cuts were high for all of the studied subjects while using insects as protein sources and legumes, to replace the soybean cake's diet in the organic broiler.

\subsection{Zoo-technical performances}

The zoo-technical performances in organic chickens are mentioned, in (Table 2).

Regarding the obtained consumption indices $(\mathrm{CI})$, the consumption indices for the two tests on organic chickens are lower than the standards declared according to the Poultry Chambers Agriculture Survey 2014 which is 3.063 for an average slaughter age of 89 days [42]. Also, those (CI) are lower than those obtained by Leiber F. and also by Juin $[30,38]$.

Table 2. Zoo-technical performances in organic chickens.

\begin{tabular}{|c|c|c|c|c|c|c|}
\hline & \multicolumn{3}{|c|}{$\frac{\text { Test 1 }}{(\mathrm{n}=20)}$} & \multicolumn{3}{|c|}{$\frac{\text { Test 2 }}{(\mathrm{n}=20)}$} \\
\hline & $\frac{\text { Unit 1 }}{(\mathrm{n}=10)}$ & $\frac{\text { Unit 2 }}{(\mathrm{n}=10)}$ & Average & $\frac{\text { Unit 1 }}{(\mathrm{n}=10)}$ & $\frac{\text { Unit } 2}{(\mathrm{n}=10)}$ & Average \\
\hline $\mathrm{CI} * * 1$ & 1.22 & 1.13 & 1.18 & 01.10 & 1.24 & 1.17 \\
\hline $\mathrm{M}^{* 2}$ & 10.00 & 0 & 5 & 20.00 & 0 & 10 \\
\hline $\mathrm{ADG}^{* * 3}$ & 1.59 & 1.46 & 1.52 & 01.29 & 1.39 & 1.34 \\
\hline CY**4 & 56.2 & 55.6 & 55.9 & 47.8 & 47.8 & 47.8 \\
\hline
\end{tabular}

Moreover, the average daily gain (ADG) is very low, they are 1.52 and 1.34 , successively for the two tests 1 and 2 , and which are lower than those obtained in organic broilers fed a diet based on insects and legumes as sources of protein [30]. The Carcass Yield (CY) shows a similarity compared to those obtained in broilers $(40.01 \%$ and $41.23 \%$ ) for both tests, respectively, using the LPF (Table 2).

\section{Conclusion}

As food waste (FW) is inevitably generated by many sectors such as households, hotels, supermarkets and restaurants, it is strongly recommended to be recovered more efficiently than to be buried as MSW.

This food waste, which accounts for a large proportion of solid household waste, is rich in carbon and nitrogen sources such as carbohydrates, proteins, and fats, which are excellent raw materials.

One of the suggested uses would certainly be to promote the recovery of these amounts of food waste as feed. In addition, these waste materials have great potential in biomass with valuable solutions to animal nutrition problems.

Based on the results obtained, the present study has proved the feasibility of reusing food waste generated in restaurants, after their stabilization, sterilization, and granulation as a food substitute for organic chicks. This could then help boost poultry production at a lower cost and ensure a balanced diet for the public. The results of this study encourage, in future studies, the promotion of the recovery of food waste as a feed for poultry while respecting the standards in force in the field of livestock besides the protection of the environment.

\section{Contribution of the authors}

L. MECHKIRROU performed the experimental design, analyzed and interpreted the data, prepared and edited the manuscript text, and ensured the publication process. M.E. AFILAL and M. OUHSSINE verified the feasibility of the experiment, compiled the data and manuscript preparation, and improved data interpretation. M. ARABI helped to the laboratory analyses, the experiment monitoring, and helped to the manuscript enhancement and linguistic style performance. 
Acknowledgement. The authors wish to thank the research teammates of "Agro-Physiology, Biotechnologies, Environment and Qualities Laboratory", The Faculty of Sciences Kenitra city. Also, the co-workers at the "Bioresources, biotechnologies, Ethnopharmacology and Health Laboratory" at the Faculty of Sciences Oujda. The authors also acknowledge all chicken farm stuff, and the veterinary Doctor M Naouaoui, for his full collaboration in the actual study.

\section{References}

1. J.D. Ferguson. Food Residue, Loss and Waste as Animal Feed. Mater. Sci. Mater. Eng., 15 (2019)

2. D. Hoornweg, P. Bhada-Tata, What a Waste: A Global Review of Solid Waste Management. Urban Dev. Ser. knowledge Pap. World Bank, 15 (2012)

3. S. Kaza, L.C. Yao, P. Bhada-Tata, F. Van Woerden. What a Waste 2.0: A Global Snapshot of Solid Waste Management to 2050. Urban Dev. World Bank, Washington, DC, 295 (2018)

4. W.L. Chow, S. Chong, J.W. Lim, Y.J. Chan, M.F. Chong, T.J. Tiong, J.K. Chin, G.T. Pan. Anaerobic co-digestion of wastewater sludge: A review of potential cosubstrates and operating factors for improved methane yield. Processes. 8, 21 (2020)

5. M. Belmakki , E.H. Bartali, H. Xiaoru, A. Bjerre, Identification and characterization of organic waste in Morocco, an important step towards the valorization of waste. Moroccan J. Agron. Vet. Sci. 3, 9(2015)

6. F. Karouach, M. Bakraoui, Y. El Gnaoui, N. Lahboubi, H. El Bari, Effect of combined mechanical - ultrasonic pretreatment on mesophilic anaerobic digestion of household organic waste fraction in Morocco. Energy Rep. 6, 5(2020)

7. M. Arabi, M. Sbaa, M. Vanclooster, A. Darmous, Impact of the municipal solid waste typology on leachate flow under semi-arid climate - A case study. J. Ecol. Eng. 21, 8 (2020)

8. G. Kibria, Food Waste Impacts on Climate Change and Water Resources. A Part of a Research Project on Community-Based Environmental and Sustainability Education Model in Australia. Tech. Rep. 4 (2017)

9. J. Xu, Q. Zhang, D. Li, J. Du, C. Wang, J. Qin, Rapid degradation of long-chaincrude oil in soil by indigenous bacteria using fermented food waste supernatant. Waste Manage. 85, 13 (2019)

10. A. Vimala Ebenezer, M. Dinesh Kumar, S. Kavitha, D. Khac Uan, J. Rajesh Banu, State of the art of food waste management in various countries. Food Waste to Valuable Resources., 25 (2020)

11. Y. Ren, M. Yu, C. Wu, Q. Wang, M. Gao, Q. Huang, $\mathrm{Y}$. Liu, A comprehensive review on food waste anaerobic digestion: research updates and tendencies. Bioresour. Technol. 247, 8 (2017)

12. G. Capson-Tojo, M. Rouez, M. Crest, J.P. Steyer, J.P. Delgenès, R. Escudié, Food waste valorization via anaerobic processes: a review. Rev Environ. Sci Biotechnol. 15, 49 (2016)

13. FAO. Food Wastage Footprint. Impacts on Natural Resources. Summary Rep., 63 (2013)

14. M. Waqas, T. Almeelbi, A.S. Nizami. Resource recovery of food waste through continuous thermophilic in-vessel composting. Environ Sci Pollut Res. 25, 12 (2018)

15. H.S. Ng, P.E. Kee, H.S. Yim, P.T. Chen, Y.H. Wei, J.C.W. Lan, Recent advances on the sustainable approaches for conversion and reutilization of food wastes to valuable bioproducts. Bioresour. Technol.. 302, 8 (2020)

16. R. Salemdeeb, E. K. H. J. zu Ermgassen, M. H. Kim, A. Balmford, A. Al-Tabbaa, Environmental and health impacts of using food waste as animal feed: a comparative analysis of food waste management options. J. Cleaner Prod., 27 (2016)

17. A.J. García, M.B. Esteban, M.C. Marquez, P. Ramos, Biodegradable municipal solid waste: characterization and potential use as animal feedstuffs. Waste Manage. 25, 8 (2005)

18. E.K.H.J. Zu Ermgassen, B. Phalan, R.E. Green, A. Balmford, Reducing the land use of EU pork production: Where there's swill, there's a way. Food Policy. 58, 14(2016)

19. R.U. Khan, S. Naz, Z. Nikousefat, V. Tufarelli, V. Laudadio, Thymus vulgaris: Alternative to antibiotics in poultry feed. World's poultry sci. assoc. 68, 8 (2012)

20. H. Zhai, H. Liu, S. Wang, J. Wu, A.M. Kluenter, Potential of essential oils for poultry and pigs. Anim. Nutr., 8 (2018)

21. M. Nikiema, J. B. Sawadogo, M. K. Somda, D. Traore, D. Dianou, A. S. Traore, Optimisation de La Production de Biométhane à Partir Des Déchets Organiques Municipaux. Int. J. Biol. Chem. Sci. 9, 14 (2015)

22. V. Francois, Détermination d'indicateurs d'accélération et de stabilisation de déchets ménagers enfouis. Etude de la recirculation de lixiviats sur colonnes de déchets. Thèse de doctorat, Université de Limoges. 197 (2004)

23. S. Aloueimine, Méthodologie de caractérisation des déchets ménagers à Nouakchott (Mauritanie) : contribution à la gestion des déchets et outils d'aide à la décision. Université de Limoges, France 195 (2005)

24. F. Charnay, Compostage des déchets urbains dans les Pays en Développement : élaboration d'une démarche méthodologique pour une production pérenne de compost, Thèse de doctorat. Université de Limoges, France 277 (2005)

25. ANSEJ. Aviculture - Elevage des Poules pondeuses Fiche technique. 8 (2010)

26. S.B. Ayssiwede, R. Missoko-Mabeki, A. Mankor, A. Dieng, M.R. Houinato, C.A.A.M. Chry-Sostome, M. Dahouda, A. Missohou, J.L. Hornick, Effets de 
l'incorporation de la farine de feuilles de Cassia tora (Linn.) dans la ration alimentaire de jeunes poulets traditionnels du Sénégal. Revue Méd. Vét. 163, 12 (2012)

27. S.B. Ayssiwede, D.F. Atakoun, Y. Issa, A. Missohou, Performances zootechnico- économiques des poulets de chair nourris de rations à base de farine de graines de roselle (Hibiscus sabdariffa, Linn.) Au sénégal. Livestock Res. Rural Dev. 27, 128 (2015)

28. S.A. Ciewe Ciake, Evaluation de l'effet de la nature et du niveau de la matière grasse alimentaire sur la productivité du poulet de chair. Thesis dissertation, Université Cheikh Anta Diop de Dakar, Mali, 100 (2006)

29. H. Bello, Essai d'incorporation de la farine de feuilles de moringa oleifera dans l'alimentation chez les poulets indigènes du sénégal: Effets sur les performances de croissance, les caractéristiques de la carcasse et le résultat économique. Thesis dissertation, Université Cheikh Anta Diop de Dakar, Mali, 119 (2010)

30. F. Leiber, T. Gelencsér, A. Stamer, Z. Amsler, J. Wohlfahrt, B. Früh, V. Maurer, Insect and legumebased protein sources to replace soybean cake in an organic broiler diet: effects on growth performance and physical meat quality. Renew. Agric. Food Syst. 7 (2016)

31. G. Papadomichelakis, A.C. Pappas, E. Tsiplakou, G.K. Symeon, K. Sotirakoglou, V. Mpekelis, K. Fegeros, G. Zervas, Effects of dietary dried olive pulp inclusion on growth performance and meat quality of broiler chickens. J. Livestock Sci., 33 (2019)

32. Y. El Gnaoui, F. Karouach, M. Bakraoui, M. Barzb, H. El Baria, Mesophilic anaerobic digestion of food waste: Effect of thermal pretreatment on improvement of anaerobic digestion process. Energy Rep. 6, 6 (2020)

33. I. Seven, T. Aksu, P.T. Seven, The Effects of Propolis and Vitamin C Supplemented Feed on Performance, Nutrient Utilization and Carcass Characteristics in Broilers Exposed to Lead. J. Livestock Sci., 148, 6 (2012)

34. J. Lacour, Valorisation de la fraction organique de résidus agricoles et autres déchets assimilés à l'aide de traitements biologiques anaérobies. Université Quisqueya, INSA de Lyon, France 218 (2012)

35. Y. Wang, Y.J. Ru, G.H. Liu, W.H. Chang, S. Zhang, H.J. Yan, A.J. Zheng, R.Y. Lou, Z.Y. Liu, H.Y. Cai, Effects of different rearing systems on growth performance, nutrients digestibility, digestive organ weight, carcass traits, and energy utilization in male broiler chickens. Livestock Sci., 6 (2015)

36. B.F. Fortuoso, J.H. Dos Reis, R.R. Gebert, M. Barreta, L.G. Griss, R.A. Casagrande, T.G. de Cristo, F. Santiani, G. Campigotto, L. Rampazzo, L.M. Stefani, M.M. Boiago, L.Q. Lopes, R.C. Santos, M.D. Baldissera, R.A. Zanette, T. Tomasi, A.S. Da Silva, Glycerol monolaurate in the diet of broiler chickens replacing conventional antimicrobials:
Impact on health, performance and meat quality. $\mathrm{J}$. Microb. Pathogenesis. 129, 7 (2019)

37. L. Dusart, Alimentation des volailles en agriculture biologique - Besoin des animaux et recommandations, Cahier technique, 68 (2015)

38. H. Juin, C. Bordeaux, D. Feuillet, A. Roinsard, Valeur nutritionnelle de sources de protéines pour l'alimentation des volailles en production biologique. 11ème JRA-FG, Tours., 68 (2015)

39. M.R. Abdollahi, V. Ravindran, B. Svihus, Pelleting of broiler diets : An overview with emphasis on pellet quality and nutritional value. J. Anim. feed sci. technol. 179, 23 (2013)

40. R. Bakhshalinejad, A. Hassanabadi, R.A. Swick, Dietary sources and levels of selenium supplements affect growth performance, carcass yield, meat quality and tissue selenium deposition in broilers. J. Anim. Nutr. 5, 8 (2019)

41. L. Carew, J. McMurtry, F. Alster, Effects of lysine deficiencies on plasma levels of thyroid hormones, insulin-like growth factors I and II, liver and body weights, and feed intake in growing chickens. Poultry Sci. 84, 6 (2005)

42. F. Morinière, S. Pattier, A. Uzureau, C. Nayet, Alimentation des volailles en agriculture biologiquela FAF en élevage avicole. Cahier Technique, 68 (2015) 